\title{
Habitual Physical Exercise and Osteoarthritis of the Knee in Female
}

\author{
Emran $\mathrm{M}^{1 *}$, Hasan $\mathrm{MI}^{2}$, Ahmed $\mathrm{SM}^{3}$, Newaz $\mathrm{F}^{4}$, Atiquzzaman $\mathrm{M}^{2}$, Rahman $\mathrm{HH}^{2}$ \\ ${ }^{1}$ Department of Physical Medicine and Rehabilitation, Khwaja Yunus Ali Medical College and \\ Hospital, Sirajganj, Bangladesh; ${ }^{2}$ Department of Physical Medicine and Rehabilitation, \\ Kurmitola General Hospital, Dhaka, Bangladesh; ${ }^{3}$ Department of Physical Medicine and \\ Rehabilitation, Bangabandhu Sheikh Mujib Medical University, Dhaka, Bangladesh; \\ ${ }^{4}$ Department of Physical Medicine and Rehabilitation, Kumudini Women's Medical College \\ and Hospital, Tangail, Bangladesh
}

\begin{abstract}
Background: The exercise is a widely promoted way to improve and maintain health, and osteoarthritis (OA) is a major health problem also. The study was conducted to examine the impact of different types of leisure-time physical activity on the OA of the knee.

Objective: The study was aimed to evaluate the association of recreational (habitual) physical activities with the osteoarthritis of the knee in the female.

Methods: The case-control study was carried out on 174 female selected purposively with the age range of $40-70$ years and above, from September 2016 to August 2017.Among them 87 were the cases with OA of the knee, and the same number of healthy females of the same age group were included as the control. Physical activity was assessed by self-reported regular exercise patterns. A structured interviewer-administered questionnaire was used to collect data.

Results: Age, educational status, occupational status and BMI were not statistically significant $(p>0.05)$ between the two groups. High level of physical activities (walking, running or jogging 20 or more miles per week) were associated with osteoarthritis of the knee, while low level of physical activities $(<10 \mathrm{miles} / \mathrm{per}$ week) and moderate level of physical activities (10-20 miles/per week) had no significant association with the osteoarthritis of the knee.

Conclusion: Based on the findings, the study suggests not to continue a high level of physical activities rather than to continue with moderate and low level of physical activity in accordance to subject's physical propensity, and endorse this note for the general health promotion.
\end{abstract}

Keywords: Osteoarthritis, Habitual physical exercise, Physical propensity, High level physical activity.

\section{Introduction}

The bio-mechanical influence of anthropometric changes and habitual physical activity levels are important linked contributory factors which may play a role in the prevalence and symptomatology of osteoarthritis in aging women. ${ }^{1}$

The beneficial health effects of physical activity are well known, include increased longevity and decreased incidence of cardiovascular disease, diabetes, obesity, and hypertension. ${ }^{2-3}$ One of the potentially hazardous effects of physical activity is osteoarthritis. ${ }^{4}$

Female gender, age, obesity, previous joint injury, occupational activities are known risk factors for both hip and knee osteoarthritis. ${ }^{5}$

*Correspondence: Mohammed Emran, Department of Physical Medicine and Rehabilitation, Khwaja Yunus Ali Medical College and Hospital,

Sirajganj,Bangladesh; e-mail: emran.pmr@gmail.com;

ORCID: 0000-0002-6744-0225
There is an increased risk of developing hip and knee OA with specific strenuous exercise and longterm physical activity were detected among general population, here wear and tear theory of joint degeneration related to repetitive joint loading..$^{6-8}$

The moderate and vigorous physical activities including recreational running do not significantly increase the risk of OA. ${ }^{9-10}$

While many kinds of physical activity require repetitive joint use that may cause cartilage attrition, physical activity can help in preventing $\mathrm{OA}$ in different ways like strengthening the muscular support around joints and thereby reduces the risk of joint injury, improve and maintains joint mobility by preventing the 
joints from 'freezing up' and physical activity helps to avoid obesity, a risk factor for some forms of OA. Finally, mature cartilage cells receive nourishment only from the diffusion of substances through the cartilage matrix from the joint fluid as because cartilage has no blood vessels or nerves, and physical activity enhances this process. ${ }^{11}$

A widely promoted way to improve and maintain health is leisure-time physical activity. The potential effect of physical activity on OA is important to understand.

Previous studies on the effect of physical activity on the knee joint have reported conflicting findings. Moreover, a few studies have been carried out on this fact in Bangladesh.

Therefore, this study was aimed to explore the interaction between physical activities with the osteoarthritis of the knee in the female.

\section{Materials and Methods}

This case-control study was conducted on 174 female participants.Data were collected using a structured interviewer-administered questionnaire, enquiring about demographic data and details of the physical activities. All procedures of this study including ethical aspects were reviewed and approved by the Institutional Review Board of the Bangabandhu Sheikh Mujib Medical University, (BSMMU) and performed following the declaration of Helsinki principles. Informed consents were obtained from all patients after explaining the nature and purpose of the study. Each patient enjoyed every right to participate or refuse or even withdraw from the study at any point in time. The study was conducted at the Department of Physical Medicine and Rehabilitation, Bangabandhu Sheikh Mujib Medical University, Dhaka, Bangladesh from September 2016 to August 2017.

The total 174 female participants were selected by purposive sampling, and were divided into the two groups where 87 patients with osteoarthritis of the knee as the case and 87 without osteoarthritis of the knee were in the control group.

Inclusion criteria for the study included (1) female, (2) age range 40 to 70 years and above,
(2) fulfill the American College of Rheumatology (ACR) clinical and radiological criteria for diagnosis of osteoarthritis, (3) doing any level of the habitual physical activity.

The exclusion criteria included (1) male, (2) secondary osteoarthritis, (3) morning stiffness more than 1 hour, (4) malignancy, tuberculosis.

Physical activity was assessed by self-reported regular exercise patterns. Among those who reported any regular exercise, three levels of activity were defined: high (those who had physical activity more than 20 miles per week); moderate (those who had physical activity between 10 and 20 miles per week); low (those who had physical activity up to 10 miles per week). The chosen basis for the physical activity index was walking, running, jogging here because they were the most common activity for this population.

Statistical analyses were carried out by using the Statistical Package for Social Sciences version 23.0. The quantitative observations were indicated by frequencies and percentages. ChiSquared test was used to analyse the categorical variables, showed with cross tabulation. The univariate logistic regression analysis was used to the regular physical activity and the results were expressed as odds ratios with $95 \%$ confidence intervals. The $p$-value of $<0.05$ was considered statistically significant. Here significant, denoted of having the association.

\section{Results}

Demographic data were obtained from all the respondents. The mean age was 57 years. Age, educational status, occupation and BMI were not statistically significant $(p>0.05)$ between the two groups. (table I)

Among the 87 patients, 55 were doing a high level of physical activities, the value was 41 in the control group and the $p$ value was significant $(<0.05)$. The low level of physical activities and a moderate level of physical activities were not statistically significant $(p>0.05)$ between the two groups. (table II) 
Table I: Demographic characteristics of the respondents

\begin{tabular}{|c|c|c|c|c|c|}
\hline & \multicolumn{2}{|c|}{$\begin{array}{c}\text { Case } \\
(n=87)\end{array}$} & \multicolumn{2}{|c|}{$\begin{array}{c}\text { Control } \\
(n=87)\end{array}$} & \multirow[t]{2}{*}{$p$ value } \\
\hline & $\mathrm{n}$ & $\%$ & $\mathbf{n}$ & $\%$ & \\
\hline \multicolumn{6}{|l|}{ Age (year) } \\
\hline $40-50$ & 31 & 35.6 & 29 & 33.3 & \multirow{4}{*}{$0.717^{\mathrm{ns}}$} \\
\hline $51-60$ & 30 & 34.5 & 25 & 28.7 & \\
\hline $61-70$ & 18 & 20.7 & 23 & 26.4 & \\
\hline$>70$ & 8 & 9.2 & 10 & 11.5 & \\
\hline \multicolumn{6}{|l|}{ Educational status } \\
\hline Illiterate & 5 & 5.7 & 8 & 9.2 & \multirow{2}{*}{$0.387^{\mathrm{ns}}$} \\
\hline Literate & 82 & 94.3 & 79 & 90.8 & \\
\hline \multicolumn{6}{|l|}{ Occupational status } \\
\hline Teacher & 31 & 35.6 & 28 & 32.2 & \multirow{7}{*}{$0.961^{\mathrm{ns}}$} \\
\hline Banker & 27 & 31.0 & 23 & 26.4 & \\
\hline Doctor & 9 & 10.3 & 11 & 12.6 & \\
\hline House wife & 8 & 9.2 & 9 & 10.3 & \\
\hline Business & 6 & 6.9 & 7 & 8.0 & \\
\hline Garment worker & 5 & 5.7 & 7 & 8.0 & \\
\hline Household worker & 1 & 1.1 & 2 & 2.3 & \\
\hline \multicolumn{6}{|l|}{ BMI $\left(\mathrm{kg} / \mathrm{m}^{2}\right)$} \\
\hline$<18.5$ & 2 & 2.3 & 3 & 3.4 & \multirow{4}{*}{$0.472^{\mathrm{ns}}$} \\
\hline $18.5-24.9$ & 44 & 50.6 & 53 & 60.9 & \\
\hline $25.0-29.9$ & 25 & 28.7 & 20 & 23.0 & \\
\hline$\geq 30.0$ & 16 & 18.4 & 11 & 12.6 & \\
\hline
\end{tabular}

Table II: Regular physical activity of the respondents

\begin{tabular}{lcccc}
\hline $\begin{array}{c}\text { Regular physical } \\
\text { activity } \\
\text { (miles/per week) }\end{array}$ & $\begin{array}{c}\text { Case } \\
(\mathbf{n = 8 7})\end{array}$ & $\begin{array}{c}\text { Control } \\
(\mathbf{n}=87)\end{array}$ & OR (95\% CI) & $\boldsymbol{p}$ value \\
\hline Low (<10) & 7 & 14 & $2.19(0.77-6.40)$ & $0.103^{\mathrm{ns}}$ \\
Moderate (10-20) & 25 & 32 & $0.69(0.35-1.37)$ & $0.258^{\mathrm{ns}}$ \\
High (>20) & 55 & 41 & $1.93(1.01-3.70)$ & $0.032^{\mathrm{s}}$ \\
\hline
\end{tabular}

$s=$ significant,$n s=$ not significant

\section{Discussion}

This case-control study on women,provides additional knowledge about the relation of physical activity to osteoarthritis of the knee.

This study proves Marti et al where they said that premature OA could happen in high-intensity exercise over a long period of time. ${ }^{12}$

Another study found an association with a two to three fold increased risk of radiologic OA of the knees and hips in women who were involved in weight-bearing sports (running, jogging, etc.) activity which is in favour of this study. ${ }^{13}$

Some studies investigated the effect of physical activity on the knee joint and reported conflicting findings. Although some of them reported that physical activity is associated with risk for knee OA. ${ }^{6,13-14}$
A study showed female gender as a significant risk factor along with the other risk factors for Knee OA among walkers and runners. ${ }^{15}$

Selected types of physical activity may initiate and/or exacerbate cartilage degeneration by transmitting repetitive impact and torsional loads to the large weight-bearing joints such as the hip and knee. ${ }^{16}$ Here the high level of physical activity was the significant one.

In this study, the moderate and low level of physical activity was not associated with the osteoarthritis of the knee and that was seen in other studies. All suggested, without significant joint injury, moderate types of physical activity do not increase the risk of OA. ${ }^{1,7,17-23}$

It was identified in a study that there was no increased risk for radiographic knee OA in middleaged and elderly persons who participated in the recreational exercise. ${ }^{24}$

Other studies observed that physical activity might have no effect or may even protect the knee joint from degenerative changes. ${ }^{8,24-26}$

The similarity of this study with others is that there is no association of the moderate level of physical activities with osteoarthritis of the knee, while it differs from that high level of physical activities, have an association.

The recommendation is to continue low level and moderate level of physical activity, and public health guideline can be followed. ${ }^{27-28}$ This could be an important message for health promotion in general and for the prevention of the knee osteoarthritis in particular.

\section{Conclusion}

This study accords a proposition about the alliance of physical activity and OA knee and encourage not to continue high level of physical activity rather than to continue with moderate and low level of physical activity in accordance to subject's physical propensity. The study also endorses this note for the general health advancement and explicitly to impede the OA of the knee.

\section{Acknowledgment}

The authors are grateful to the BSMMU, Dhaka for providing a grant to conduct this study. Authors also sincerely thank the participants of the study. 
Conflict of interest: The authors declared no conflict of interest.

Funding: Bangabandhu Sheikh Mujib Medical University (BSMMU), Dhaka.

Ethical approval: IRB of BSMMU.

Submitted:29 $9^{\text {th }}$ July, 2019

Final revision received: $15^{\text {th }}$ March, 2020

Accepted: $19^{\text {th }}$ March, 2020

Published: $1^{\text {st }}$ August, 2020

\section{References}

1. White JA, Wright V, Hudson AM. Relationships between Habitual Physical Activity and Osteoarthrosis in Ageing Women. Public Health. 1993; 107: 459-70.

DOI: $10.1016 / \mathrm{s} 0033-3506(05) 80172-6$

2. Pate R, Pratt M, Blair S, Haskell W, Macera C, Bouchard C, et al. Physical activity and public health: a recommendation from the Centers for Disease Control and Prevention and the American College of Sports Medicine. JAMA. 1995; 273:402-7.

DOI: $10.1001 /$ jama.273.5.402

3. Blair S, Kohl H, Barlow C, Paffenbarger R, Gibbons $\mathrm{L}$, Macera C. Changes in physical fitness and allcause mortality: a prospective study of healthy and unhealthy men. JAMA. 1995; 273:1093-98.

PMID: 7707596

4. Pate R, Macera C. Risks of exercising: Musculoskeletal injuries. In: Bouchard C, Shepard $\mathrm{R}$, Stephens T, editors. Physical activity, fitness and health: international proceedings and consensus statement. Champaign, IL: Human Kinetics Publishers, 1994: 1008-18.

\section{DOI: 10.1249/00005768-199401000-00024}

5. Felson D, Zhang Y. An update on the epidemiology of knee and hip osteoarthritis with a view to prevention. Arthritis Rheum. 1998; 41: 1343-55. DOI: $10.1002 / 1529-0131(199808) 41: 8<1343:: A I D-$ ART3>3.0.CO;2-9

6. Cheng Y, Macera C, Davis D, Ainsworth B, Troped P, Blair S. Physical activity and self-reported, physician-diagnosed osteoarthritis: Is physical activity a risk factor? J ClinEpidemiol. 2000;53:315-22. DOI: $10.1016 / \mathrm{s} 0895-4356(99) 00168-7$

7. Cooper C, Snow S, McAlindon T, Kellingray S, Stuart B, Coggon D et al. Risk factors for the incidence and progression of radiographic knee osteoarthritis. Arthritis Rheum. 2000;43:995-1000. DOI: 10.1002/1529-0131(200005)43:5<995:AIDANR6>3.0.CO;2-1
8. Hart D, Doyle D, Spector T. Incidence and risk factors for radiographic knee osteoarthritis in middle-aged women: the Chingford Study. Arthritis Rheum. 1999;42:17-24.

DOI: 10.1002/1529-0131(199901)42:1<17:AID-

ANR2>3.0.CO;2-E

9. Hannan M, Felson D, Anderson J, Naimark A. Habitual physical activity is not associated with knee osteoarthritis: the Framingham Study. J Rheumatol. 1993;20:704-9.

PMID: 8496869

10. Lane N, Oehlert J, Bloch D, Fries J. The relationship of running to osteoarthritis of the knee and hip and bone mineral density of the lumbar spine: a 9-year longitudinal study. J Rheumatol. 1998;25:334-41. PMID: 9489830

11. Hall AC, Urban JPG, Gehl KA. The effects of hydrostatic pressure on matrix synthesis in articular cartilage. J Orthop Res. 1991;9:1-10.

DOI: $10.1002 /$ jor.1100090102

12. Marti B, Tschopp KA, Jucker A, Howald H. Is excessive running predictive of degenerative joint disease?. Controlled study of former elite athletes. BMJ.1989;299: 91-93.

DOI: $10.1136 / \mathrm{bmj} .299 .6691 .91$

13. Spector TD, Harris PA, Hart DJ, Cicuttini FM, Nandra D, Etherington J, et al. Risk of osteoarthritis associated with long-term weight-bearing sports: a radiologic survey of the hips and knees in female exathletes and population controls. Arthritis Rheum. 1996;39:988-95.

DOI: $10.1002 /$ art.1780390616

14. Szoeke C, Dennerstein L, Guthrie J, Clark M, Cicuttini F. The relationship between prospectively assessed body weight and physical activity and prevalence of radiological knee osteoarthritis in postmenopausal women. J Rheumatol.2006;33:1835-40. PMID: 16881096

15. Gabriel SE. Update on the epidemiology of the rheumatic diseases. Curr Opin Rheumatol.1996; 8:96-100. DOI: $10.1097 / 00002281-199603000-00002$

16. Buckwalter J, Lane N. Athletics and osteoarthritis. Am J Sports Med. 1997;25:873-81. DOI: $10.1177 / 036354659702500624$

17. Hootman JM, Macera CA, Helmick CG, Blair SN. Influence of physical activity-related joint stress on the risk of self-reported hip/knee osteoarthritis: a new method to quantify physical activity. Prev Med.2003;36:636-44.

DOI: $10.1016 / \mathrm{s} 0091-7435(03) 00018-5$

18. Sandmark H, Vingard E. Sports and risk for severe osteoarthritis of the knee. Scand J Med Sci Sports. 1999;9:279-84.

DOI: $10.1111 /$ j.1600-0838.1999.tb00246.x

19. Panush RS, Schmidt C, Caldwell JR, Edwards NL, Longley $\mathrm{S}$, Yonker $\mathrm{R}$, et al. Is running associated 
with degenerative joint disease?JAMA. 1986; 255: 1152-54.

DOI: 10.1001/jama.1986.03370090074023

20. Cooper C, McAlindon T, Snow S, Vines K, Young P, Kirwan J, et al. Mechanical and constitutional risk factors for symptomatic knee osteoarthritis: differences between medial tibiofemoral and patellofemoral disease. J Rheumatol. 1994;21:301-13. PMID: 8182642

21. Bagge E, Bjelle A, Eden S, Svanborg A. Factors associated with radiographic osteoarthritis: results from the population study 70 -year old people in Goteborg. J Rheumatol. 1991;18:1218-22. PMID: 1941827

22. Lau E, Cooper C, Lam D, Chan V, Tsang K, Sham A. Factors associated with osteoarthritis of the hip and knee in Hong Kong Chinese: obesity, joint injury and occupational activities.Am $\mathrm{J}$ Epidemiol.2000;152:855-62.

DOI: $10.1093 /$ aje/152.9.855

23. Manninen P, Riihimaki H, Heliovaara M, Suomalainen O. Physical exercise and risk of severe knee osteoarthritis requiring arthroplasty. J Rheumatol. 2001;40:432-37.

DOI: $10.1093 /$ rheumatology/40.4.432
24. Felson D, Niu J, Clancy M, Sack B, Aliabadi P, Zhang Y.Effect of recreational physical activities on the development of knee osteoarthritis in older adults of different weights: The Framingham Study. Arthritis Rheum.2007; 57:6-12.

DOI: $10.1002 /$ art.22464

25. Rogers LQ, Macera CA, Hootman JM, Ainsworth $\mathrm{BE}$, Blair SN. The association between joint stress from physical activity and self-reported osteoarthritis: an analysis of the Cooper Clinic data. Osteoarthritis and Cartilage.2002; 10: 617-22.

DOI: 10.1053/joca.2002.0802

26. Urquhart DM, Soufan C, Teichtahl AJ, Wluka AE, Hanna F, Cicuttini FM. Factors that may mediate the relationship between physical activity and the risk for developing knee osteoarthritis. Arthritis Research and Therapy. 2008;10:203. DOI: $10.1186 / \operatorname{ar} 2343$

27. U.S. Department of Health and Human Services. Healthy People 2010. Washington, DC: U.S. Department of Health and Human Services, 2000.

28. U.S. Department of Health and Human Services. Physical Activity and Health: A Report of the Surgeon General. Atlanta, GA: U.S. Department of Health and Human Services, Centers for Disease Control and Prevention, National Center for Chronic Disease Prevention and Health Promotion 1996. 